\title{
POSSIBILIDADES PARA A IMPLEMENTAÇÃO DA MEDIA- ÇÃO PENAL RESTAURATIVA JUVENIL NO CHILE: DESAFIOS E PERSPECTIVAS COM BASE NO ABOLICIONISMO PENAL
}

\author{
POSSIBILITIES FOR THE IMPLEMENTATION OF JUVENILE \\ RESTORATIVE CRIMINAL JUSTICE IN CHILE: CHALLENGES AND \\ PERSPECTIVES BASED ON CRIMINAL ABOLITIONISM
}

\author{
Rosane Teresinha Carvalho Porto" \\ DANIEL ACHUTTI"*
}

\section{RESUMO}

O presente estudo tem por objetivo analisar as possibilidades para a implementação da Justiça Restaurativa no Chile, por meio da mediação penal juvenil. Considera-se importante e atual o tema, em virtude dos desafios e das perspectivas com base no abolicionismo penal da criminologia crítica de Hulsman e Nils Christie. Neste contexto, questiona-se: quais são os avanços e os desafios para implementação da Justiça Restaurativa a enfrentar diante da cultura social e jurídica do Chile? Em termos conclusivos, a respeito da legislação juvenil chilena esta precisa ser revista e revisitada, pois a falta de especialização aos juízes e promotores, bem como, o paradigma punitivo com relação aos adolescentes, dificultam a conexão e o desenho institucional de implementação e efetivação das práticas de Justiça Restaurativa no país através de uma política pública. Em matéria metodológica, utiliza-se

\section{ABSTRACT}

The purpose of this study is to analyze the possibilities for the implementation of Restorative Justice in Chile, through juvenile criminal mediation. The issue is considered important and current because of the challenges and perspectives based on the criminal abolitionism of critical criminology by Hulsman and Nils Christie. In this context, it is questioned: what are the advances and the challenges for the implementation of Restorative Iustice to face before the social and legal culture of Chile? In conclusive terms, regarding Chilean youth legislation, this needs to be reviewed and revisited, since the lack of specialization of judges and prosecutors, as well as the punitive paradigm with respect to adolescents, make it difficult to connect and design institutional implementation and implementation of Restorative Justice practices in the country through a public

* Pós-doutoranda em Direito pela Universidade La Salle (RS). Doutora em Direito pela UNISC. Mestre em Direito na área de concentração: Políticas Públicas de Inclusão Social com bolsa da Coordenação de Aperfeiçoamento de Pessoal de Nível Superior - CAPES. Professora na Universidade Regional do Noroeste do Estado do Rio Grande do Sul - UNIJUí, lecionando na graduação em Direito e no Programa de Pós Graduação em Direito - Mestrado e Doutorado. Professora na graduação em direito e na Pós Lato Sensu na UNISC (Universidade de Santa Cruz do Sul). Estuda temáticas voltadas a criança e adolescente, violência, criminologia, gênero, direitos sociais, Acesso à Justiça e Direitos Humanos. E-mail: rosaneporto@unisc.br.

* Doutor em Ciências Criminais pela PUCRS (2012), com período sanduíche na Universidade de Leuven - Bélgica (2010/2011). Professor Permanente do Mestrado em Direito e do Curso de Direito da Universidade La Salle (RS). Coordenador da Área de Direito e Política da Universidade La Salle (RS). Visiting Scholar na Università IUAV di Venezia, Itália (20142015), e no Leuven Institute of Criminology - Universidade de Leuven, Bélgica (2013-2014 e 2017-2018). Advogado. Tem experiência na área de Direito, com ênfase em Direito Penal e Processual Penal, Criminologia, Justiça Restaurativa e Justiça Criminal.

E-mail: daniel.achutti@achuttiesorio.com.br 
como método de abordagem o materialismo dialético e como técnica de pesquisa a documental e a bibliográfica.

PALAVRAS-CHAVE: Abolicionismo Penal. Adolescentes. Chile. Justiça Restaurativa. policy. In methodological matters, dialectical materialism is used as a method of approach and as documentary and bibliographical research technique.

KEYWORDS: Adolescents. Chile. Penal Abolitionism. Restorative Justice.

\section{INTRODUÇÃO}

Ao analisar as possibilidades para a implementação da Justiça Restaurativa no Chile, por meio da mediação penal restaurativa juvenil ${ }^{1}$, considera-se importante e atual o tema, em virtude dos desafios e as perspectivas com base no Abolicionismo Penal da criminologia crítica de Hulsman, Nils Christie e a pensadora Elliott com a sua abordagem teórica e prática a respeito da Justiça restaurativa para a estruturação de um modelo crítico para a América Latina.

Em outras palavras, é preciso utilizar a perspectiva abolicionista de Hulsman e de Nils Christie para trabalhar com a lógica do crime enquanto situação-problema e, bem como, desapropriar alguns conflitos da Justiça Criminal, para então, buscar enfrentar com seriedade o encarceramento de jovens segregados e o descaso estatal com as vítimas de um sistema reprodutor e que perpetua a lógica punitiva.

Para tanto, o objetivo do referido artigo está em observar como ocorreu ou está se dando a implementação da Justiça Restaurativa no Chile; e como problema de investigação: quais são os avanços e os desafios para implementação da Justiça restaurativa a enfrentar diante da cultura social e jurídica do Chile? Utilizar-se-á o método de abordagem o materialismo dialético e como técnica de pesquisa a documental e a bibliográfica.

\section{A EXPERIÊNCIA DA MEDIAÇÃO PENAL RESTAURATIVA NO CHILE}

Inicialmente, importa mencionar o aporte histórico de construção e elaboração legislativa no Chile, tendo como principal lei a Lei de Responsabilidade Penal Juvenil. A Lei n. 20.084/2007 (Lei de Responsabilidade Penal Juvenil) que entrou em vigência no dia 8 de junho de 2007, estabelecendo a Mediação Penal Juvenil, propôs uma grande reforma quanto a punição de delitos simples, com o jovem menor de dezoito anos, tratando o adolescente "[...] como un sujeto de derecho que debe ser protegido en su desarrollo e inserción social y lograr objetivos de prevención del delito" ${ }^{2 "}$.

1 Expressão utilizada no Chile.

2 COUSO, Jaime. Justicia y derechos del niño. Notas para un estudio sobre la especialidad del derecho penal y procesal penal de adolescentes: el caso de la ley chilena. Colombia: Unicef, 2008, p. 97. 
A mencionada legislação considera como imputáveis os adolescentes entre 14 e 17 anos de idade. Para as autoras, também a Lei de Responsabilidade Penal Juvenil estabelece um sistema de garantias aos adolescentes, envolvendo os atores especializados na justiça, como: os juízes, os advogados, os defensores públicos. E também conta com as sanções penais distintas e equiparadas conforme a gravidade do delito ${ }^{3}$.

Para Gude 4 identifica-se a mediação penal como sendo uma prática específica de Justiça restaurativa, embora a associação entre ambos estes conceitos não seja pacífica ou unânime. No Chile, a possibilidade de desenvolvimento da mediação penal de maneira formal ou institucionalizada, iniciou no legislativo, pela primeira vez, com a Reforma Processual Penal, que desde dezembro do ano 2000 tinha vigência de maneira gradual nas distintas regiões do país.

El nuevo Código Procesal Penal incorporó las llamadas Salidas Alternativas al Proceso Penal (mediación penal para adultos) que constituyen formas de término anticipado al proceso, establecidas como excepción al principio de legalidad en la persecución penal, y que implican el reconocimiento por parte del Estado de la necesidad de establecer mecanismos de solución al conflicto penal distintos al proceso penal y la pena tradicionales. Estas Salidas Alternativas consisten básicamente en la Suspensión Condicional del Procedimiento y los Acuerdos Reparatorios 5 .

Durante 2015, o Ministério da Justiça e Direitos Humanos começou a liderar vários grupos de trabalho intersetoriais para discutir aspectos críticos específicos da Lei de Responsabilidade Penal Juvenil. Discutiram a possibilidade de implementar a Justiça Restaurativa, uma vez que é uma abordagem internacionalmente válida e reconhecida, dada a sua harmonia com a Convenção e utilizada em diferentes países, incluindo os da América Latina ${ }^{6}$.

Como resultado dessa reunião, no início de 2016, a Unidade de Coordenação e Estudos pertencente ao Ministério da Justiça e Direitos Humanos começou a projetar um Estudo Prático de mediação penal para os adolescentes

3 QUILODRÁN; C. R.; LABRENZ, C.; MORALES, G. D. Justicia Restaurativa en Sistemas de Justicia Penal Juvenil Comparado: Suecia, Inglaterra, Italia y Chile. Revista Política Criminal, Chile, v. 13, n. 25, p. 626-649, jul. 2018.

4 GUDE, Alejandra Diáz. La experiencia de la mediación penal en Chile. Revista Política Criminal, Chile, v. 5, n. 9, p. 01-67, jul. 2010.

5 GUDE, Alejandra Diáz. La experiencia de la mediación penal en Chile, p. 06.

6 O referido relatório tratou de discorrer a respeito do projeto incipiente sobre a Justiça Restaurativa no Chile, mais precisamente da mediação penal fruto de debates entre membros do Ministério da Justiça e Direitos Humanos, que ocorreu a partir de 2015 e em face as necessidades de mudanças da legislação juvenil para atendimento a reinserção social dos adolescentes. Por conta disso, iniciou a implementação da mediação penal em alguns casos no ano de 2016-2017. Este foi considerado o projeto Piloto do Chile. Também como parceira para elaboração e acompanhamento desse projeto piloto, a Universidade de Ciências Humanas do Chile tendo à frente alguns especialistas, a citar a pesquisadora e coordenadora do projeto Daniela Bolívar e ainda outros pesquisadores fora do Chile, enquanto Assessor Internacional o Doutor Ivo Aertsen. 
que cometem infrações. A iniciativa foi motivada pela necessidade de melhorar a aplicação do atual sistema de responsabilidade criminal adolescente (RPA) em relação aos princípios da Convenção sobre os Direitos da Criança e outros instrumentos internacionais sobre justiça juvenil. Depois de vários meses de preparação, o estudo prático começou a ser implementado através da contratação de um mediador, reportando-se diretamente ao Ministério da Justiça e Direitos Humanos desde outubro de 2016. Os encaminhamentos começaram a ser promovidos a partir de dezembro, chegando ao primeiro caso em fevereiro do ano de $2017^{7}$.

Corrobora-se a respeito do processo de implementação da mediação penal restaurativa juvenil por meio das iniciativas dos atores sociais como se deu o convênio de colaboração:

El compromiso fue materializado con un "Convenio" de colaboración para la derivación de casos a la mediación penal juvenil y Estudio Práctico firmado por el Ministerio Público, la Defensoría Penal Pública y el MJYDH, pensando en poder analizar la posibilidad especifica de incluir procesos de mediación penal para jóvenes infractores y definir criterios y metodologías para la incorporación de un futuro Programa Nacional de Mediación Penal Juvenil dentro del contexto de las reformas a la LRPA, especificamente en el nuevo Servicio Nacional de Reinserción Social Juvenil. Dicho documento asume el sentido estratégico de ocupar el espacio de la carencia legislativa sobre la materia en el país para efectos de validar el trabajo institucional y viabilizar la iniciativa, vinculando simbólicamente a las máximas autoridades de las instituciones, siendo la primera vez que se hace un Convenio con estas características en Chile. Dentro de este documento, se unieron ciertos criterios para su ejecución de la experiencia, fruto de la mesa de trabajo compuesta por los actores del nivel nacional de cada institución, y que constituye el "Protocolo de Derivación” de los casos. Desde la Unidad de Coordinación y Estudios perteneciente al MJYDH se comenzó a diseñar y luego de varios meses de preparación, el EP comenzó a implementarse. Desde el nivel nacional de ambas instituciones, en la misma instancia de la mesa de trabajo que resultó en el Convenio, se definió que en su primer año sería implementación en la Fiscalia Regional Centro Norte. Luego, la Defensoría Penal Pública Norte asume como la "contraparte" por ser ahi donde se tratan los casos específcamente relacionados a responsabilidad penal adolescente, que es el contexto de implementación de la experiencia. Actualmente, dicha experiencia fue expandida y también está siendo implementada en la ciudad de Valparaíso. En el EP se definió por primera vez una cobertura que promoviera el acceso a la mediación penal, de casos de mayor relevancia en comparación a las experiencias anteriores. Además, se definió un modelo de gestión y se establecieron requisitos específicos de derivació $n^{8}$.

7 BOLÍVAR, Daniela (Coord). Capacitación, asesoría y estudio práctico mediación penal juvenil. Informe final. Chile: Facultad de Ciencias Sociales - Universidad de Chile, out. 2017.

8 MIRANDA, Paula (Coord.). Elaboración de un sistema de supervisión para la mediación penal en el marco del nuevo servicio de reinserción social juvenil. Informe final. Chile: Facultad de Ciencias Sociales - Universidad de Chile, out. 2018, p. 57. 
Em abril de 2017, tem-se a lei que cria o Novo Serviço de Reinserção Social e introduz alterações à Lei n. 20.084/2017, estabelecendo um serviço nacional guiada pelos princípios da especialidade, intersetorialidade e descentralização.

El nuevo Servicio Nacional de Reinserción Social introduce modificaciones específicamente en el ámbito del sistema de justicia criminal juvenil, esencialmente a la LRPA, adoptando dentro de sus fundamentos la creación de un programa de mediación penal como medida de diversificación reconocida. Es en este contexto de revisión de la respuesta estatal a los jóvenes infractores de ley que el Ministerio de Justicia y Derechos Humanos de Chile (en adelante MJYDH) asume la responsabilidad de promover enfoques consistentes con la CDN en el abordaje de la problemática, posicionando la JR y la mediación penal como una prioridad'.

Conforme tabela abaixo sobre os Elementos do Protocolo de Derivação dos casos de Estudo Prático, observa-se uma seleção de população beneficiária, bem como a natureza leve dos crimes ou delitos cometidos pelos adolescentes, que poderão ser recepcionados pela mediação penal restaurativa juvenil. Ao analisar estes recortes categóricos, deixando os crimes graves fora da proposta, percebe-se a fragilidade e limitação da prática restaurativa.

9 MIRANDA, Paula. Elaboración de un sistema de supervisión para la mediación penal en el marco del nuevo servicio de reinserción social juvenil, p. 57. 


\section{TABELA 01: ELEMENTOS DO PROTOCOLO DE DERIVAÇÃO DE CASOS DO ESTUDO PRÁTICO}

\begin{tabular}{|c|c|}
\hline CATEGORÍAS & CONTENIDO \\
\hline \multicolumn{2}{|r|}{ Población Beneficiaria } \\
\hline \multirow{5}{*}{ Cobertura } & $\begin{array}{l}\text { Jóvenes a quienes se les impute la comisión de una falta o } \\
\text { simple delito de naturaleza penal, cuya responsabilidad se } \\
\text { rija por la Ley } 20.084\end{array}$ \\
\hline & $\begin{array}{l}\text { Víctimas de faltas o simples delitos de naturaleza penal, } \\
\text { imputados a jóvenes cuya responsabilidad se rija por la Ley } \\
20.084\end{array}$ \\
\hline & $\begin{array}{l}\text { Al menos una de las partes del conflicto deberá tener domicilio } \\
\text { o residencia en alguna de las comunas de competencia de la } \\
\text { Unidad de Justicia Vecinal de Norte (Renca, Independencia, } \\
\text { Cerro Navia, Pudahuel y Quilicura) o Poniente (Estación } \\
\text { Central) }\end{array}$ \\
\hline & Espacial \\
\hline & $\begin{array}{l}\text { Territorio correspondiente a la Fiscalía Regional } \\
\text { Metropolitana Centro Norte (en adelante FRMCN) }\end{array}$ \\
\hline \multicolumn{2}{|c|}{$\begin{array}{c}\text { Naturaleza de la infracción: falta o simple delito. Se excluyen expresamente los } \\
\text { siguientes: }\end{array}$} \\
\hline \multirow{6}{*}{$\begin{array}{l}\text { Requisitos de } \\
\text { derivación }\end{array}$} & Delitos dolosos contra la vida \\
\hline & Delitos contra la libertad ambulatoria \\
\hline & $\begin{array}{l}\text { Delitos contra la libertad sexual cometidos contra personas } \\
\text { menores de edad }\end{array}$ \\
\hline & $\begin{array}{l}\text { Delitos y faltas tipificados en la ley } 20.000 \text {, a excepción de los } \\
\text { previstos en los artículos } 4^{\circ}, 8^{\circ} \text { y } 50 .\end{array}$ \\
\hline & Delitos cometidos en contexto de violencia intrafamiliar. \\
\hline & $\begin{array}{l}\text { Infracciones penales que involucren el uso de armas y/o } \\
\text { violencia en las personas, aquellos en que el infractor tenga } \\
\text { condenas previas y cuando el infractor no se encuentre } \\
\text { escolarizado o no esté dispuesto a hacerlo como condición } \\
\text { previa para la derivación o como parte de una condición de } \\
\text { una suspensión condicional del procedimiento posterior a la } \\
\text { mediación }\end{array}$ \\
\hline \multicolumn{2}{|c|}{$\begin{array}{l}\text { Estado del proceso: pre-judicial, judicializados o sentenciados a trabajos en } \\
\text { beneficio de la comunidad o reparación del mal causado. }\end{array}$} \\
\hline
\end{tabular}

Fonte: Miranda ${ }^{10}$.

10 MIRANDA, Paula. Elaboración de un sistema de supervisión para la mediación penal en el marco del nuevo servicio de reinserción social juvenil, p. 59. 
No Chile há uma instituição responsável de implementar os programas de reparação de dano e conta com quatro deles distribuídos em distintas regiões do país. Cada um deles, conta com uma dupla psicossocial constituída por um trabalhador social (Assistente Social) e um psicólogo responsável pelo processo. Em uma entrevista realizada pelas autoras, no Chile não há um programa específico e especializado em mediação penal juvenil; e no programa de reparação de dano, os entrevistados mencionaram receber em médio cinco casos por ano, bem como relataram que os promotores, advogados, defensores e juízes aplicam com frequência a sanção penal ao adolescente e não tem como prática fazer o encaminhamento dos casos para a instituição responsável. Uma das dificuldades enfrentadas pelo programa está na distribuição geográfica dos casos, em um território de 16.000 quilômetros quadrados ${ }^{11}$.

Além disso, os mesmos profissionais atendem casos no programa de serviços em benefício da comunidade, também direcionados aos adolescentes. No entanto, e por ser um número maior de casos; em torno de 20 , prejudica a qualidade nos atendimentos; especialmente no programa de reparação de dano, aonde envolve a prática vítima ofensor na mediação. A demora no contato com o adolescente e a continuidade com o trabalho fragiliza o resultado restaurativo. O perfil dos adolescentes é amplo, alguns tem grande envolvimento com o crime, outros pouco, as famílias são vulneráveis e não participam do programa. Portanto, o sistema chileno é punitivo, visibiliza a vítima e o adolescente.

Em suma no Chile não existem centros que abordem especificadamente a mediação entre adolescentes e as vítimas. As práticas restaurativas são isoladas. Umas das razões, está no caráter punitivo do sistema penal do Chile. Para o recepcionamento da Justiça restaurativa, o sistema penal do Chile precisa escutar o adolescente e investir em políticas públicas de prevenção, abrindo-se para possibilidades contemporâneas e humanistas ${ }^{12}$. No mesmo sentido:

El desarrollo de este tipo de práctica aún son tímidas en el país, persistiendo el desafio de trabajar en una política nacional tendiente a hacerla efectiva, como lo que ha sucedido en el caso de la mediación familiar. La mediación como la práctica restaurativa más implementada en el contexto chileno, originalmente estuvo más bien conectada a una técnica de resolución de conflictos en la esfera civil y comunitaria, trasladándose luego hacia el ámbito penal. Muchas de esas iniciativas de mediación han sido entendidas como "restaurativas", lo que establece un importante avance de las concepciones sobre mediación penal en el medio nacional, que, a pesar de su origen en el contexto de familia, civil y comunitario, camina hacia las concepciones propias de la justicia restaurativa. La mediación penal comenzó a desarrollarse en Chile desde el año 2000, con al menos 20 iniciativas implementadas hasta la fecha. En su

11 QUILODRÁN; C. R.; LABRENZ, C.; MORALES, G. D. Justicia Restaurativa en Sistemas de Justicia Penal Juvenil Comparado: Suecia, Inglaterra, Italia y Chile.

12 QUILODRÁN; C. R.; LABRENZ, C.; MORALES, G. D. Justicia Restaurativa en Sistemas de Justicia Penal Juvenil Comparado: Suecia, Inglaterra, Italia y Chile. 
gran mayoría, se implementaron en el contexto de justicia de adultos. Se han realizado pocos estudios evaluando estas experiencias, lo que González \& Fuentealba justifican por su ausencia de formalización y su incipiente y esporádica utilización en el país. En su mayoría estas iniciativas han sido implementadas como "programas experimentales, siguiendo protocolos de otras realidades legislativas o adecuando metodologías utilizadas en la mediación familiar, regulada legalmente en Chile”. Además, se indica que los programas implementados en Chile hasta ahora, por lo general no consideran la participación del entorno social, la familia y la sociedad civil ${ }^{13}$.

Por conta dessas circunstâncias em especial, da necessidade de se desenvolver a mediação penal restaurativa juvenil, refutando o cunho punitivo com o adolescente, o projeto desenvolvido pelo Ministério da Justiça e Direitos Humanos sugeriu na sua primeira análise algumas recomendações, entre elas: a continuidade, a divulgação e multiplicação dos programas e práticas de mediação e outros modelos como conferências, ampliando, selecionando, apoiando e registrando o número de casos a serem abordados no programa de mediação existente, com a finalidade de padronização e qualificação dos atendimentos em curto prazo de tempo ${ }^{14}$.

Por conta disso, houve a preocupação por parte do Ministério da Justiça em elaborar um sistema de supervisão para mediação penal a ser recepcionada no Novo Serviço de Reinserção Social Juvenil. Os objetivos específicos são: elaborar proposta de normativa técnica do serviço prestado; desenhar um instrumento avaliativo dos processos e da qualidade da mediação penal e elaborar orientações para implementar os processos de supervisão das práticas de justiça restaurativa ${ }^{15}$.

A partir da análise conceitual por meio da literatura nacional e internacional, destacando as normativas internacionais e as latino-americanas com perspectiva restaurativa no contexto juvenil; projetaram-se as oito (8) etapas para implementação da prática restaurativa para os jovens no Chile. Salienta-se que o país chileno se encontra entre as etapas 7 e 8, ou seja, na etapa 7: fase de sensibilizar e convencer os responsáveis políticos, para a continuidade do projeto. E na etapa 8: a sustentabilidade. Por isso, mister o estabelecimento de indicadores de qualidade e supervisão para a pratica se manter e poder tornar-se uma política pública ${ }^{16}$.

Com base no Observatório Internacional Justiça Juvenil, adotou-se o modelo holístico constituído este, por quatro níveis; reconhecendo no terceiro

13 MIRANDA, Paula. Elaboración de un sistema de supervisión para la mediación penal en el marco del nuevo servicio de reinserción social juvenil, p. 35.

14 BOLÍVAR, Daniela. Capacitación, asesoría y estudio práctico mediación penal juvenil.

15 MIRANDA, Paula. Elaboración de un sistema de supervisión para la mediación penal en el marco del nuevo servicio de reinserción social juvenil, p. 38.

16 MIRANDA, Paula. Elaboración de un sistema de supervisión para la mediación penal en el marco del nuevo servicio de reinserción social juvenil, p. 40. 
nível a implementação da mediação penal juvenil como uma prática ou política de prevenção aos jovens; objetivando evitar o contato dele com o sistema penal criminal. Adotou-se tais modelos, para redesenhar uma política pública não punitiva e sim responsiva ao adolescente chileno.

No entanto, a dúvida está se é possível propor a mediação penal restaurativa juvenil dentro da Lei de Responsabilidade Penal. Ao redesenhar e pensar no novo Serviço de Reinserção Social Juvenil, as etapas, os níveis e os desafios precisarão ser enfrentados, dando seguimento aos pontos elaborados e sugeridos no informe final a pedido do Ministério da Justiça e dos Direitos Humanos do Chile.

No próximo capítulo analisar-se-á como é possível trabalhar com a mediação penal restaurativa juvenil se a lei de Responsabilidade penal juvenil

\section{POSSIBILIDADES E ENTRAVES DE SE TRABALHAR A MEDIA- ÇÃO PENAL RESTAURATIVA NA LEI DE RESPONSABILIDADE PENAL JUVENIL?}

Neste capítulo abordar-se-á a possibilidade de aplicação da mediação penal restaurativa juvenil, mesmo não sendo recepcionada pela Lei de Responsabilidade Penal. Adianta-se a possibilidade com a implementação da mediação penal juvenil pelo Novo Serviço de Reinserção Social.

No Chile, a lei $n^{\circ}$ 19.334/1994 tornou obrigatória a conciliação prévia quando o caso envolver adolescentes e houver interesse público. O Código de Processo Penal no país ainda prevê a possibilidade de acordo entre vítima e ofensor para a obtenção de reparação em alguns crimes patrimoniais. Os promotores têm autorização para mediarem os casos penais, ou encaminhá-los para mediação em órgãos externos ${ }^{17}$. No entanto, não tem incorporado no seu sistema as práticas restaurativas, primando pela corresponsabilidade e política de proteção integral aos jovens adolescentes.

Em 2002 o governo enviou o projeto de Lei de Responsabilidade Penal dos Adolescentes por infrações a lei penal para ser discutido no Parlamento. Em termos gerais, as diferenças do Anteprojeto de 1998 e do projeto de 2002 dão conta dos "rasgos" coercitivos do sistema. E atualmente se propõe alterações a esta Lei, envolvendo a política pública de um Novo Serviço de Reinserção Social, prevendo a mediação penal restaurativa juvenil.

A proposta de alterações na Lei de Responsabilidade Penal, prevendo indiretamente a mediação penal restaurativa no Chile, atenderia as normativas internacionais dos direitos da criança e do adolescente, com a criação de um Sistema de Proteção Integral, diferenciando a resposta penal juvenil com relação

17 CARVAlHO, Camilo de Oliveira. Mediação penal não paralela e integrada à justiça restaurativa: uma proposta de efetivação do acesso à justiça no Brasil, 2014. Dissertação (mestrado) - Universidade Federal da Bahia, Faculdade de Direito, 2014. 
aos adultos. Atualmente os procedimentos restaurativos recepcionados pela reforma processual penal carecem de formalização legal e de reconhecimento válido e expresso para lograr acordos na esfera penal, por isso, a mediação penal ainda segue desafios no sistema penal para melhorar o acesso à justiça no Chile, e ainda, possibilitar maior participação e apoio as vítima e a comunidade ${ }^{18}$.

Portanto, o atual sistema de responsabilidade penal adolescente do Chile não constitui, um sistema independente e devidamente especializado. O anteprojeto de 1998, continha um desenho mais especializado e, por sua vez, também contemplava "regras" institucionais mais compatíveis com a integração de um paradigma restaurativo, especialmente em termos de desjudicialização, reparação e limitações da privação da liberdade. Ao se vincular a discussão ou o debate sobre a reforma processual penal, aproximando com a necessidade de desenhar, propor um sistema de responsabilidade penal ao adolescente, de acordo com as exigências da Convenção dos Direitos da Criança, se incitou e preteriu a lógica da seguridade de cidadania e uma demanda de maior punição, impondo-se uma espécie de peso entre eficiência e garantias ${ }^{19}$.

Os fatores estruturais na legislação, bem como as limitadas possibilidades para integrar elementos restaurativos, podem ser significativos para a inviabilidade da implementação e o processo contínuo da Justiça restaurativa para os adolescentes que incorrem em crimes. Importa mencionar, devido a ausência de ser a lei considerada uma legislação especializada; pois não contempla um juizado especializado para o atendimento dos adolescentes nestas circunstâncias e nem de crianças e adolescentes vítimas de violações de direitos. Não houve a mudança de linguagem e paradigma, sendo o rito recepcionado pelo Justiça Criminal (penal e processo penal). Portanto, sob a lógica restaurativa, todo o desenho legal da LRPA deve ser revisado, a fim de cumprir com os padrões internacionais relacionados à política de proteção aos direitos das crianças e dos adolescentes ${ }^{20}$.

A mediação penal pode ser compreendida como um sistema de gestão de conflitos, definido como aquele em que uma parte neutra, de natureza técnica e com conhecimento adequado, independente dos atores institucionais do processo penal, e imparcialmente, ajuda duas ou mais pessoas envolvidas em um delito ou falta, como vítima e infrator, a compreender a origem do conflito, suas causas e consequências, confrontar seus pontos de vista e elaborar acordos sobre o modo de reparação, material e simbólico.

18 MIRANDA, Paula. Elaboración de un sistema de supervisión para la mediación penal en el marco del nuevo servicio de reinserción social juvenil, p. 40.

19 MERA, Alejandra. Reforma a la justicia penal adolescente: ¿Por qué no dar un giro hacia la justicia restaurativa? Santiago de Chile: Anuar Quesille, 2018.

20 MERA, Alejandra. Reforma a la justicia penal adolescente: ¿Por qué no dar un giro hacia la justicia restaurativa? 
As Nações Unidas definem programas de mediação penal como serviços que atendem às necessidades das vítimas do delito, incentivando os infratores a assumir responsabilidade por seus atos. A mediação penal compartilha os objetivos da mediação em geral, na medida em que visa promover um diálogo respeitoso entre os envolvidos sobre a origem do conflito, promovendo a compreensão mútua dos interesses entre eles e a sua integração em uma solução considerada satisfatória subjetivamente para a pacificação do relacionamento conflitivo. A mediação penal também pode usar modelos tradicionais de mediação, como o Modelo de Harvard ou o Modelo Transformador ${ }^{21}$.

Com relação aos objetivos da mediação destacam-se: a revalorização da vítima, possibilitando a sua fala; proporcionar um espaço seguro para comunicação entre a vítima, ofensor e a comunidade.

A mediação penal restaurativa juvenil, numa perspectiva de administração da justiça, a mediação penal pode ser entendida como uma forma alternativa de resolver o conflito criminal, visando principalmente a obtenção de um acordo reparatório entre vítima e agressor, a fim de evitar a acusação e promover a seletividade do sistema de ação penal em relação a delitos mais graves. No entanto, a mediação penal juvenil deve ser entendida, principalmente, como uma metodologia de intervenção do fenômeno da infração adolescente, que não termina com a obtenção de um acordo entre os afetados ${ }^{22}$.

A perspectiva restauradora tem o potencial de melhorar as chances para os sistemas de justiça juvenil cumprir seu fim central. Mera ${ }^{23}$ faz algumas sugestões, entre elas, a criação de uma justiça especializada aos adolescentes que tenha seu próprio procedimento, assegurando o princípio do contraditório e da ampla defesa em todos os graus de recursos; estabelecer um sistema judicial de execução com competência e funções claras, bem como a intervenção de promotores e defensores que devidamente acompanham; Criar unidades especializadas de justiça criminal para adolescentes na polícia (Delegacias especializadas da Criança e do Adolescentes); projetar incentivos institucionais na justiça juvenil para a capacitação dos profissionais; Gerar um sistema que permita aos tribunais especializados acessar informações relevantes sobre a situação pessoal do adolescente, objetivando a tomada de decisões devidamente informadas nas audiências e nos casos de desjudicialização.

Outras propostas seriam o reforço a desjudicialização nos casos de primeiro contato do adolescente com o sistema, associando sempre que possível um conteúdo restaurativo que não implica um alto grau de intervenção (por

21 GUDE, Alejandra Diáz. La experiencia de la mediación penal en Chile.

22 MIRANDA, Paula. Elaboración de un sistema de supervisión para la mediación penal en el marco del nuevo servicio de reinserción social juvenil.

23 MERA, Alejandra. Reforma a la justicia penal adolescente: ¿Por qué no dar un giro hacia la justicia restaurativa? 
exemplo, desculpas à vítima) e a garantia de que esse tipo de medida, bem como as demais já expostas, sejam aplicadas quando houver evidências da prática de um crime pelo adolescente. Além disso, busca-se a garantia de participação voluntária no processo restaurativo pré-judicial, para o qual deve ser assegurado o aconselhamento jurídico relevante, inclusão na política criminal do Ministério Público em matéria de reparação à vítima, solução de conflitos penal ou conveniência para o bem-estar do adolescente para que assim sejam promovidos os devidos critérios de desjudicialização ${ }^{24}$.

A formulação final da Lei n. 20.084 não inclui qualquer regulamentação especial dos acordos de reparação, pois contém a proposta original de 2002, que permitia uma ampla aplicação desses acordos, sem as restrições do artigo 241 da Convenção. O Código de Processo Penal permite acordos de reparação apenas no caso de crimes de natureza patrimonial, lesões menos graves e atos ilícitos. As razões para rejeitar a proposta original durante o processo parlamentar foram baseadas na impressão feita pelos parlamentares que esse tipo de acordo representaria a impunidade, especialmente quando se trata de crimes graves ${ }^{25}$.

Os acordos de reparação foram incluídos no Código de Processo Penal com o objetivo expresso de fornecer uma instância para a satisfação dos interesses da vítima através de reparação. Portanto, representam um espaço de desenvolvimento natural para a justiça restaurativa, desde que sejam associados com a realização de um processo restaurativo entre a vítima e o ofensor. Para ficar longe da própria ideia de um cálculo de negociação, o conjunto de infrações deve promover uma reparação pertinente a vítima, e não econômica. Este último, principalmente, por dois motivos: primeiro, porque, de outro modo, arrisca- esse tipo de alternativas ser usado de maneira discriminatória, tornando possível apenas para os acusados que podem pagar o dinheiro economicamente; e segundo, porque outros tipos de reparação, tais como pedido de desculpas ou a realização de trabalhos em nome da vítima ou da comunidade, têm mostrado uma sensação revigorante e são muitas vezes preferido para as vítimas no contexto da justiça penal juvenil26.

Por conta disso recomenda-se ainda: a incorporação na LRPA de uma disposição que indique que o Ministério Público e o juiz devem propor a opção restaurativa às partes, quando aplicável e possível, e encaminhar os casos para esses processos para que os envolvidos decidam voluntariamente sobre a participação. É especialmente recomendado que os programas de justiça restaurativa não sejam confinados a crimes leves ou de menor potencial ofensivo, uma vez

24 MERA, Alejandra. Reforma a la justicia penal adolescente: ¿Por qué no dar un giro hacia la justicia restaurativa?

25 MERA, Alejandra. Reforma a la justicia penal adolescente: ¿Por qué no dar un giro hacia la justicia restaurativa?

26 MERA, Alejandra. Reforma a la justicia penal adolescente: ¿Por qué no dar un giro hacia la justicia restaurativa? 
que nesses casos os efeitos destes tipos de programas restaurativos são menos eficazes e, em muitos casos, a melhor resposta do sistema voltar-se-ia a não intervenção. Se assim for, a justiça restaurativa pode correr o risco de expandir a rede de controle do sistema penal e, por outro lado, não oferecer alternativas para a resolução de conflitos ${ }^{27}$.

Em relação ao tipo de processo restaurativo que seria aconselhável implementar, existe uma variedade de alternativas. Por um lado, a mediação vítima-ofensor representa um modelo mais próximo da cultura jurídica e da prática de resolução de conflitos no Chile. Enquanto isso, conferências restaurativas tem a vantagem de incluir, além do adolescente e a vítima, outras pessoas, ambos membros da família e da comunidade ou serviços sociais, que possam apoiar o processo de prestação de contas e execução da reparação acordado no processo ${ }^{28}$.

Sabe-se que o maior problema dos países não é a falta de regras, ou leis. A América Latina se destaca por ter boas leis nacionais e regionais, além de ter assinado os principais instrumentos legais internacionais. A dificuldade mais importante, então, reside na aplicação dessas leis, regulamentos, protocolos e outros instrumentos legais que os Estados ratificaram ou aprovaram. Por conta disso: como traduzir leis e regulamentos em políticas públicas eficazes? Como medir os impactos dessas leis e suas mudanças concretas, significativas e duradouras na situação dos adolescentes, as suas vítimas e a sociedade em geral? Como superar as limitações financeiras, técnicas e humanas dos Estados, que em muitos casos não dispõem de recursos suficientes para aplicar na prática o que as normas estabelecem, mesmo que tenham muita vontade política?

\section{DESAFIOS E PERSPECTIVAS A PARTIR DO ABOLICIONISMO PENAL: A NECESSIDAE DA JUSTIÇA SOCIAL NA JUSTIÇA RESTAURATIVA}

A abordagem conceitual sobre a Justiça restaurativa no Chile e em alguns países especialmente da América Latina mudam de um lugar para o outro, mas não deixam dúvidas sobre a lógica de romper com a retribuição da pena e ir ao encontro da restauração do diálogo, do respeito pelo outro nas relações humanas. No entanto, algo ainda não está claro e nem superado, necessitando também ser enfrentado pelos adeptos as práticas restaurativas, que é a necessidade ou o sentido de justiça social neste contexto. Elliott menciona em seu trabalho Ruth Morris acerca do assunto, mais especificadamente crítica "a teoria da Justiça restaurativa por sua falta de atenção a temas de justiça social”"

27 MERA, Alejandra. Reforma a la justicia penal adolescente: ¿Por qué no dar un giro hacia la justicia restaurativa?

28 MERA, Alejandra. Reforma a la justicia penal adolescente: ¿Por qué no dar un giro hacia la justicia restaurativa?

29 ELLIOTT, Elizabeth. Segurança e cuidado: justiça restaurativa e sociedades saudáveis. São 
A teoria da Justiça Restaurativa não leva em conta as enormes injustiças estruturais na base do nosso Sistema de Justiça, nem a extensão na qual elas reforçam o racimo e o classicismo. Qualquer teoria ou método que ignore o racismo e o classicismo, que são básicos para Justiça Retributiva, está deixando algo muito importante de fora, e servirá para reforçar este mesmo racismo e classicismo mais adiante, por não questioná-los $[\ldots]^{30}$.

Nesse contexto há ainda a correlação com o abolicionismo penal, pois este defende a própria extinção do sistema punitivo, até a sua forma mais radical, que refuta toda a forma de castigo, pois como responsabilizar o adolescente em um país constituído por injustiças sociais? ${ }^{31}$ As visões simplistas do direito penal, não contemplam a complexidade da vida humana, onde, acordo com Achutti e Leal ${ }^{32}$ o enfoque nos atos e não nas interações cria uma visão distorcida e estagnada que não condiz com a realidade, pois as relações são dinâmicas, inclusive em relação à posição de vítima e ofensor.

Diante disso, entende-se que a punição tem a ver com a imposição intencional de danos por agentes autorizados ao propósito - seja o Estado, o diretor da escola ou os pais. Punição denota imposição de dor injustificada, no contexto de uma sociedade regida pelo Estado de Direito. Quanto ao desejo coletivo de punir, este, é claro, precede a habilidade criminal da lei de punir. Em outras palavras, a justiça não pode se resumir a lei, ao direito ou sistema retributivo, pois não é um problema jurídico e sim, um problema humano ${ }^{33}$. Notadamente de um sujeito multidimensional: físico, político, econômico, espiritual e social. Portanto, o eu e as suas relações.

Desvelar a realidade posta sobre o ápice abissal que implica a desigualdade social é trabalhar para além das suas consequências nas instituições judiciárias e as prisionais, por exemplo, é se despir da naturalização apresentada sobre a realidade social. A realidade social naturalizada torna as pessoas ou os sujeitos incapazes de perceber a dimensão complexa e intersubjetiva nas práticas de controle, dominação e distinção de classes $^{34}$. Nas palavras do autor:

[...] o nosso pensamento social muda o racismo explícito da cor da pele para um racismo implícito, e por conta disso torna-se muito mais perigoso. Onde reside o racismo implícito do nosso culturalismo? Ora, precisamente no aspecto principal de todo racismo, que é a separação ontológica entre seres humanos de primeira classe e seres humanos de segunda classe. Assim, racismo é

Paulo: Palas Athena, 2018, p. 249.

30 ELLIOTT, Elizabeth. Segurança e cuidado: justiça restaurativa e sociedades saudáveis, p. 239.

31 ELLIOTT, Elizabeth. Segurança e cuidado: justiça restaurativa e sociedades saudáveis.

32 ACHUTTI, D.; LEAL, M.A. S. Justiça Restaurativa no Centro judiciário de Solução de Conflitos e Cidadania: da teoria à prática. Revista de Criminologia e Políticas Criminais, Maranhão, v. 3, n. 2, p. 84-100, jul./dez. 2017.

33 ELLIOTT, Elizabeth. Segurança e cuidado: justiça restaurativa e sociedades saudáveis.

34 SOUZA, Jesse. Subcidadania brasileira: para entender o país além do jeitinho brasileiro. Rio de Janeiro: Leya, 2018. 
não apenas a separação dos seres humanos por raças distintas, mas qualquer separação que construa uma distinção ontológica, independente da experiência concreta, entre os seres humanos ${ }^{35}$.

De igual modo, pensar com base nesta perspectiva é relembrar e compreender as implicações e as consequências da desigualdade social no sistema prisional, bem como as categorias construídas pelo Direito Penal contemporâneo que atende o atual sistema de justiça, servindo como ferramenta desumanizadora e de reprodução das mais diversas violências contra o ser humano.

Portanto, ao se buscar a Justiça restaurativa enquanto outra maneira de se pensar e viver a justiça nas relações, deseja-se um direito integrador e não com a lógica punitiva, meramente reprodutora de discriminações raciais e de campos de isolamento e segregação das minorias sociais. O que se pode observar é que o sistema prisional é secular, que a sua política de extermínio e segregação se perpetuou até a modernidade, passando de estágios da corporificação das penas nas prisões. E ao que parece, pode continuar sendo uma promessa a pós-modernidade ${ }^{36}$.

A Justiça restaurativa não pode ser exercida meramente na sistematização da Justiça Criminal, ou de qualquer outra sistematização. Deve representar quem somos, bem como a resposta que damos a problemas cotidianos, buscando uma maior independência diante das instituições governamentais no trato de determinados conflitos, tornando assim o cidadão mais comprometido com a comunidade e competente para o trato justo em um possível enfrentamento ${ }^{37}$.

Para os abolicionistas, o crime não tem realidade ontológica, não é produto humano e sim produto legislativo. As instituições do Estado são coorporativas e se preocupam mais com os seus problemas que o do outro. Ao se olhar para as 207 milhões de pessoas no Brasil, e os índices de violência (homicídios), percebe-se o alto índice de pessoas encarceradas, que são jovens e negras. Associado a isso, tem-se a extrema desigualdade social no país. Será que, nesse "Estado da Arte", em um sistema onde mais se prende, a utilização da Justiça restaurativa como a solução de tudo, não se está a tratando sem cientificidade, trazendo ainda mais problemas no futuro? A Justiça restaurativa tem limites, não serve para tudo. É preciso adotar uma perspectiva com base nas evidências científicas.

A prisão para Christie é um sofrimento não-criador, carente de sentido. As regras internas fazem prevalecer as relações de passividade, agressividade e dependência-dominação, que não deixam lugar para a iniciativa e nem para o diálogo, alimentando o desprezo da pessoa. No cárcere se perde a personalidade e a sociabilidade e pensa-se que quem está na nesta condição teve o que merecia.

35 SOUZA, Jesse. Subcidadania brasileira: para entender o país além do jeitinho brasileiro, p. 10.

36 ACHUTTI, Daniel Silva. Justiça restaurativa e abolicionismo penal. São Paulo: Saraiva, 2014.

37 ELLIOTT, Elizabeth. Segurança e cuidado: justiça restaurativa e sociedades saudáveis. 
Uma das críticas ao modelo abolicionista aponta para a excessiva e ingênua confiança na vítima; também que o seu futuro papel protagonista que deve ir necessariamente acompanhado de uma diminuição do poder dos órgãos estatais para impor a solução, ou seja, de um modelo de Estado diferente ${ }^{38}$.

Os abolicionistas Hulsman e Nils Christie consideram que o sistema penal intervém em muitos pontos que as pessoas envolvidas não vivenciam como delitos, esquecendo-se da vítima no processo. Sustentam também que a intervenção do sistema penal agrava os conflitos e opera na lógica do castigo, porque impede de chegar qualquer resposta que não seja punitiva. Reconhecem que a prisão é reprodutora de criminalidade, sendo apenas uma alternativa à tortura e à pena de morte. Significa dizer, "Na prisão, os homens são despersonalizados e dessocializados" ${ }^{39}$.

De qualquer sorte, o discurso abolicionista é de reformar a culpa e a pena, pois é sabido que esta não regenera, nem atribui a responsabilidade individual e coletiva efetivamente. Nesse contexto, reconhece-se que o abolicionismo não é um novo paradigma e sim uma teoria, pois serve para sensibilizar e gerar maiores interrogações, sobre o que está posto no campo social, retroalimentado pela cultura jurídica punitiva e não declarada ${ }^{40}$.

Com efeito, Hulsman e Celis ${ }^{41}$ não vê sentido nas penas, até porque entende que a administração de conflitos pelo Estado precisa ser repensada, abolida, diga-se de passagem, descentralizada, ou seja, de retirar do poder público a autonomia na regulação de conflitos, pois a estrutura das sanções apenas retroalimenta o poder simbólico do sistema penal. É necessário um sistema de administração de conflitos mais autônomo, parecido com algumas comunidades tribais, dando-se a regulação de conflitos no nível de intergrupos e de relações diretas entre indivíduos com a ajuda de instituições ou procedimentos próximos e que observem a experiência direta das pessoas para se trabalhar com dimensão da ética, do cuidado com o outro e da responsabilidade dos atos decididos e tomados pelo indivíduo.

Ademais, o abolicionismo de Mathiesen é muito especial, pois não trata de abolir algo e sim de esclarecer, de convidar a pensar sobre o sistema de penas que está posto e aplicado dentro das sociedades. Em outras palavras, implica abolir com um sistema social repressivo, partindo da reflexão, em que é fundamental romper com a ordem estabelecida e ao mesmo tempo enfrentar o

38 ELBERT, Carlos Alberto. Novo manual de criminologia. Porto Alegre: Livraria do Advogado, 2009.

39 HULSMAN, L.; CELIS, J. Penas perdidas: o sistema penal em questão. Niterói: Luam, 1993, p. 63.

40 CHRISTIE, Nils. Conflicts as Property. British Journal of Criminology, Delinquency and Deviant Social Behaviour, Inglaterra, v. 17, n. 1, jan. 1977.

41 HULSMAN, L.; CELIS, J. Penas perdidas: o sistema penal em questão. 
que está posto, para reconstruir algo. Sobre a fundamentação metodológica do abolicionismo de Foucault, assim como para Deleuze, a libertação da diferença exige um pensamento sem contradição, sem dialética, sem negação: um pensamento do múltiplo, da multiplicidade nômade e dispersa que não é limitado ou confinado pelas restrições da semelhança. $\mathrm{O}$ abolicionismo está relacionado com o princípio da solidariedade, pela abordagem humanista em relação aos excluídos e ou marginalizados sociais.

O pensamento abolicionista é fundamental ser retomado para a propositura de outras modalidades de administração de conflitos na justiça criminal. Sendo assim, a Justiça restaurativa pode ser uma outra possibilidade de repensar e enfrentar a política de encarceramento.

A Justiça restaurativa não é uma invenção ilustrada da academia ou de legisladores, mas reflete as tentativas criativas de seus praticantes de encontrar meios mais satisfatórios de lidar com os eventos danosos. A realização de uma conferência, de uma mediação ou de um círculo restaurativo, dentre outras formas a tentar atingir os resultados que se espera de um evento restaurativo (reparação dos danos, restauração dos relacionamentos rompidos etc.), conforme as suas peculiaridades, e isto apenas é possível por não haver regramento delimitado, típico do sistema de justiça criminal tradicional: diante da ausência de uma sinalização prévia do que é e do que não é crime, assim como de sanções predeterminadas para cada conduta e de um processo estabelecido (com suas regras, prazos e formas), o que existe são valores e princípios, que servirão como guias para a condução das experiências restaurativas, independentemente da forma a ser utilizada ${ }^{42}$.

Para Ballesteros, os programas e as experiências de Justiça restaurativa não se restringem a área da justiça criminal. No entanto, não basta a sua implementação dentro do sistema criminal, mister transformá-lo, pois a Justiça restaurativa tem seus próprios valores e princípios ${ }^{43}$.

Então ao mesmo instante que emerge esta possibilidade de se trabalhar com a Justiça restaurativa na justiça criminal, e não, somente com a justiça juvenil, percebe-se os limites restaurativos, a partir de conceitos sobre a Justiça restaurativa, quando reduzem a complexidade da prática judicial ou extrajudicial a um processo.

No entanto, a Justiça restaurativa tem limites e alguns desafios a serem enfrentados, são eles: a desigualdade social (o racismo, a condição econômica, o feminismo, o patriarcalismo), o encarceramento em massa, o conservadorismo judicial (tradição-segurança jurídica, poder, a baixa integração do Judiciário com a sociedade civil (centros comunitários). O foco acentuado na Justiça

42 ACHUTTI, Daniel Silva. Justiça restaurativa e abolicionismo penal, p. 67.

43 BALLESTEROS, Alejandra Mera González. Justicia restaurativa y proceso penal garantías procesales: límites y posibilidades. Revista Ius et Praxis, Chile, a. 15, n. 2, p. 165-195, 2009. 
Juvenil, sem impacto ou pouco na justiça de adultos e a fragilidade do ensino jurídico com outras possibilidades de administração dos conflitos, a necessidade de autonomia da justiça criminal.

Caminhar nesta direção impõe um pensar, necessariamente, coletivo, que interpele a todos os atores comprometidos no processo das mudanças e dos conceitos positivistas e punitivistas, em especial das mitologias que não se adequam ao paradigma emergente. Essa é uma exigência que tem profunda implicação prática em todo o edifício restaurativo, que não se consolidará em plenitude se não superar, estruturalmente, os velhos alicerces e se não satisfizer certos requisitos, que são simultaneamente epistemológicos e políticos.

A título de exemplificação no Brasil, os desafios com a Justiça restaurativa, necessitam entre tantas coisas mencionadas anteriormente, a superação dos significados e (pre)conceitos do positivismo criminológico e jurídico, adotando um outro vocabulário. Além disso, precisa superar o entendimento de ser apenas um método resolutivo condutas de baixa ofensividade ${ }^{44}$. Portanto, como pensar em um modelo ideal de Justiça restaurativa no Chile e na América Latina?

\section{CONCLUSÃO}

O referido artigo teve por premissa inicial apresentar os resultados parciais do um estudo de estágio de doutoramento sobre as possibilidades, obstáculos, desafios e perspectivas para implementação da Justiça restaurativa ou mediação penal juvenil no Chile, a partir do abolicionismo penal.

A experiência do Chile, mesmo incipiente dada nos últimos anos tem muito a dizer e a ser explorada pelos outros países da América Latina, em especial o Brasil sobre qual o sentido e a utilidade da Justiça restaurativa nos conflitos, bem como, aprofundar e enfrentar a questão da Justiça social. Nessa seara, questionou-se: quais as possibilidades para implementação e os enfrentamentos fundantes da Justiça restaurativa no Chile?

O primeiro capítulo, tratou da experiência da mediação penal no Chile, tendo como base de aplicabilidade jurídica a lei de Responsabilidade Penal Juvenil. Por sua vez, no segundo capítulo houve a preocupação e explorar se a lei de Responsabilidade Penal Juvenil, recepciona Justiça restaurativa. Pode-se verificar, que são necessárias mudanças legislativas, e bem como mudança de paradigma cultural no que tange a responsabilização pelos crimes juvenis para não terem um viés retributivo-punitivo.

Com relação a legislação juvenil Chilena esta precisa ser revista e revisitada, pois a falta de especialização aos juízes e promotores, bem como o para-

44 BRASIL,CNJ.RelatórioAnalíticoPropositivoJustiçaPesquisaDireitoseGarantiasFundamentais: pilotando a justiça restaurativa: o papel do Poder Judiciário. 2018. Disponível em: http://www. cnj.jus.br/files/conteudo/arquivo/2018/06/48a-1d20e9350d40373889719054070b0.pdf. Acesso em: 01 jul. 2019. 
digma punitivo com relação aos adolescentes, dificultam a conexão e o desenho institucional de implementação e efetivação das práticas de Justiça restaurativa no País. Embora o Ministério da Justiça e de Direitos Humanos tenha um convênio com a Universidade Católica Chilena para a elaboração da política do Novo Serviço de Reinserção Social, por meio da mediação penal restaurativa juvenil, os entraves não se esgotam nessa etapa. Mister um trabalho contínuo de sensibilização, capacitação e formação de pessoas, atores ou protagonistas ligados diretamente com a parcela populacional juvenil e beneficiária.

No terceiro capítulo, alinhado aos capítulos anteriores, com base na reflexão abolicionista, reforçou-se a necessidade de rever e ampliar o sentido de justiça para o social. Nesse sentido, corrobora o entendimento de se pensar no enfrentamento de temas como a desigualdade social (o racismo, a condição econômica, o feminismo, o patriarcalismo), o encarceramento em massa, o conservadorismo judicial, o foco acentuado na Justiça penal Juvenil, sem impacto ou pouco na justiça de adultos e a fragilidade do ensino jurídico com outras possibilidades de administração dos conflitos, bem como a necessidade de autonomia da justiça criminal, para então poder se tornar uma via de humanização dos sujeitos de direitos.

\section{REFERÊNCIAS}

ACHUTTI, D.; LEAL, M. A. S. Justiça Restaurativa no Centro judiciário de Solução de Conflitos e Cidadania: da teoria à prática. Revista de Criminologia e Políticas Criminais, Maranhão, v. 3, n. 2, p. 84-100, jul./dez. 2017.

ACHUTTI, Daniel Silva. Is a Critical Model of Restorative Justice Possible? A Penal Abolitionist Approach. In: AERTSEN, I.; PALI B.; de (Org.). Critical Restorative Justice. Blooms Bury, 2017.

ACHUTTI, Daniel Silva. Justiça restaurativa e abolicionismo penal. São Paulo: Saraiva, 2014.

AZEVEDO, R. G. O movimento da informatização da justiça. In: CARVALHO, S; WUNDERLICH, A. (Orgs). Diálogos sobre a justiça Dialogal Teses e antíteses sobre os processos: De informalização e privatização da Justiça penal. Rio de Janeiro: Lumen Juris, 2002. p. 65-69.

BALLESTEROS, Alejandra Mera González. Justicia restaurativa y proceso penal garantías procesales: límites y posibilidades. Revista Ius et Praxis, Chile, a. 15, n. 2, p. 165-195, 2009.

BOLÍVAR, D. et al. Estudio Proyecto Capacitación, Asesoría y Estudio Práctico Mediación Penal Juvenil. Informe Final. Santiago: Facultad de Ciencias Sociales, Universidad de Chile, 2017. 
BOLÍVAR, Daniela (Coord). Capacitación, asesoría y estudio práctico mediación penal juvenil. Informe final. Chile: Facultad de Ciencias Sociales - Universidad de Chile, out. 2017.

BRASIL. CNJ. Relatório Analítico Propositivo Justiça Pesquisa Direitos e Garantias Fundamentais: pilotando a justiça restaurativa: o papel do Poder Judiciário. 2018. Disponível em: http://www.cnj.jus.br/files/conteudo/arquivo/2018/06/48a-1d20e9350d40373889719054070b0.pdf. Acesso em: 01 jul. 2019.

BRASIL. Presidência da República. Secretaria Geral e Secretaria Nacional da Juventude. Mapa do encarceramento: os jovens do Brasil. Brasília: Presidência da República, 2015.

CARVALHO, Camilo de Oliveira. Mediação penal não paralela e integrada à justiça restaurativa: uma proposta de efetivação do acesso à justiça no Brasil, 2014. Dissertação (mestrado) - Universidade Federal da Bahia, Faculdade de Direito, 2014.

CHRISTIE, Nils. Conflicts as Property. British Journal of Criminology, Delinquency and Deviant Social Behaviour, Inglaterra, v. 17, n. 1, jan. 1977.

COUSO, Jaime. Justicia y derechos del niño. Notas para un estudio sobre la especialidad del derecho penal y procesal penal de adolescentes: el caso de la ley chilena. Colombia: Unicef, 2008.

CPP. Centro de Políticas Públicas. Sistema carcelario en Chile: propuestas para avanzar hacia una mayor efectividad y reinserción. Pontificia Universidad Católica de Chile, 2017. Disponível em: politicaspublicas.uc.cl/wp-content/ uploads/2017/05/Artículo-Sistema-carcelario-en-Chile.pdf. Acesso em 01 jul. 2019.

ELBERT, Carlos Alberto. Novo manual de criminologia. Porto Alegre: Livraria do Advogado, 2009.

ELLIOTT, Elizabeth. Segurança e cuidado: justiça restaurativa e sociedades saudáveis. São Paulo: Palas Athena, 2018.

FELIX, Criziany Machado. Conferência dos Ministros de Justiça dos países ibero-americanos - secretaria geral. Mapeamento de normas e leis sobre justiça restaurativa. Programa Eurosocial: Apoio ao Acesso à Justiça Componente: Fortalecimento dos Mecanismos Alternativos de Solução de Conflitos (MASC) na América Latina. Nov. 2013. Disponível em: http://www.maparegional.gob. ar/accesoJusticia/documents/verDocumento.html?idDocumento=14. Acesso em: 01 jul. 2019. 
GOMES, Daniel. IDH mostra o Brasil distante do 'pódio' do desenvolvimento humano. Jornal O São Paulo, 2017. Disponível em: https://www.fespsp.org.br/ upload/usersfiles/Paulo\%20Silvino.pdf. Acesso em: 01 jul. 2019.

GUDE, Alejandra Diáz. La experiencia de la mediación penal en Chile. Revista Política Criminal, Chile, v. 5, n. 9, p. 01-67, jul. 2010.

HULSMAN, L.; CELIS, J. Penas perdidas: o sistema penal em questão. Niterói: Luam, 1993.

HUMAN DEVELOPMENT REPORTS. Human Development Indices and Indicators. Statistical Update. 2018. Disponível em: http://hdr.undp.org/sites/ default/files/2018_human_development_statistical_update.pdf $>$. Acesso em: 01 jul. 2019.

MERA, Alejandra. Reforma a la justicia penal adolescente: ¿Por qué no dar un giro hacia la justicia restaurativa? Santiago de Chile: Anuar Quesille, 2018.

MIRANDA, Paula (Coord.). Elaboración de un sistema de supervisión para la mediación penal en el marco del nuevo servicio de reinserción social juvenil. Informe final. Chile: Facultad de Ciencias Sociales - Universidad de Chile, out. 2018.

QUILODRÁN; C. R.; LABRENZ, C.; MORALES, G. D. Justicia Restaurativa en Sistemas de Justicia Penal Juvenil Comparado: Suecia, Inglaterra, Italia y Chile. Revista Política Criminal, Chile, v. 13, n. 25, p. 626-649, jul. 2018.

SCHEERER, H.; CHRISTIE, S. Abolicionismo penal. Buenos Aires: Ediar, 1989.

SOUZA, Jesse. Subcidadania brasileira: para entender o país além do jeitinho brasileiro. Rio de Janeiro: Leya, 2018.

Recebido em: 14/04/2020.

Aprovado em: 18/05/2021. 
